\title{
Influence of diabetes on survival in patients with cystic fibrosis before and after lung transplantation
}

Don Hayes, Jr, MD, MS, ${ }^{\text {a,b,c,d }}$ Alpa V. Patel, MD, ${ }^{\text {,dd }}$ Sylvester M. Black, MD, PhD, ${ }^{c}$

Karen S. McCoy, MD, ${ }^{\mathrm{a}, \mathrm{d}}$ Stephen Kirkby, MD, ${ }^{\mathrm{a}, \mathrm{d}, \mathrm{d}}$ Joseph D. Tobias, MD, ${ }^{\mathrm{e} f}$ Heidi M. Mansour, PhD, ${ }^{\mathrm{g}}$ and

Bryan A. Whitson, $\mathrm{MD}, \mathrm{PhD}^{\mathrm{c}}$

\section{ABSTRACT}

Background: The influence of diabetes mellitus (DM) on survival in patients with cystic fibrosis $(\mathrm{CF})$ before and after lung transplantation is not well studied.

Methods: To determine the influence of DM in patients with $\mathrm{CF}$, the United Network for Organ Sharing database (2005-2013) was queried for 2 cohorts: firsttime lung transplant candidates who were not transplanted and first-time transplant recipients.

Results: A total of 679 patients with CF had data on DM status at listing and did not undergo transplantation. In this cohort, DM was associated with significant increase in mortality hazard as shown by an adjusted multivariate Cox model fitted to the whole cohort (hazard ratio [HR], 1.4; 95\% confidence interval [CI], 1.1-1.8; $P=.012$ ) and by a Cox model stratified on pairs of DM and non-DM patients matched on the propensity of having DM at listing (HR, 1.9; 95\% CI, 1.2-2.9; $P=.003$ ). In comparison, a total of 1464 patients with CF had data on DM status at listing and received a transplant, but DM at listing was not associated with posttransplant survival. The lack of association between DM and mortality hazard was evident in a multivariate Cox regression model fitted to the whole sample (HR, 1.0; $95 \% \mathrm{CI}, 0.82-1.2 ; P=.98)$ and a Cox regression model stratified on matched pairs of DM and non-DM patients (HR, $1.1 ; 95 \% \mathrm{CI}, 0.82-1.5 ; P=.56$ ).

Conclusions: The presence of DM is associated with significantly increased risk for death in patients with CF on the wait list before lung transplantation, but does not influence survival after transplantation. (J Thorac Cardiovasc Surg 2015;150:707-13)

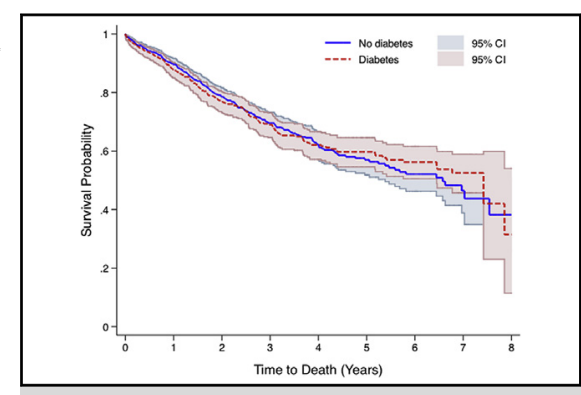

Diabetes did not influence survival in patients with cystic fibrosis after lung transplantation.

\section{Central Message}

There is significant risk of death associated with diabetes in patients with $\mathrm{CF}$ who were listed for LTx but did not undergo transplant since the inception of the LAS.

\section{Perspective}

Diabetes influences survival in patients with $\mathrm{CF}$ on the wait list for LTx but not after transplant; therefore, clinicians need to consider better management strategies for this patient population with advanced lung disease to optimize their opportunity for transplant because diabetes at wait listing does not increase mortality after LTx.

See Editorial Commentary page 714

\section{Supplemental material is available online.}

Cystic fibrosis (CF) is an inherited multisystem disease most frequently associated with chronic respiratory infections and bronchiectasis that ultimately requires lung transplantation (LTx) for a significant number of

\footnotetext{
From the Departments of ${ }^{\mathrm{a}}$ Pediatrics, ${ }^{\mathrm{b}}$ Internal Medicine, ${ }^{\mathrm{c}}$ Surgery, and ${ }^{\mathrm{e}}$ Anesthesiology, The Ohio State University College of Medicine, Columbus, Ohio; ${ }^{\mathrm{d}}$ Section of Pulmonary Medicine and ${ }^{\mathrm{f}}$ Department of Anesthesiology \& Pain Medicine, Nationwide Children's Hospital, Columbus, Ohio; and ${ }^{g}$ Skaggs Pharmaceutical Sciences Center, University of Arizona College of Pharmacy, Tucson, Ariz.

Received for publication Feb 6, 2015; revisions received May 6, 2015; accepted for publication June 3, 2015; available ahead of print July 22, 2015.
}

patients. $^{1-3}$ A common and important comorbidity is CF-related diabetes (CFRD). The incidence of CFRD is correlated with older age, $\mathrm{CF}$ transmembrane conductance regulator class, female gender, worse pulmonary function, liver dysfunction, pancreatic insufficiency, and corticosteroid use. ${ }^{4} \mathrm{~A}$ recent study reported a prevalence of CFRD of $2 \%$ in children, $19 \%$ in adolescents, and $40 \%$ to $50 \%$ in adults. 4

\footnotetext{
Address for reprints: Don Hayes, Jr, MD, MS, The Ohio State University, Nationwide Children's Hospital, 700 Children's Dr, Columbus, OH 43205 (E-mail: hayes. 705@osu.edu). $0022-5223 / \$ 36.00$

Copyright $(2015$ by The American Association for Thoracic Surgery http://dx.doi.org/10.1016/j.jtcvs.2015.06.041
} 


$$
\begin{aligned}
& \text { Abbreviations and Acronyms } \\
& \begin{aligned}
\text { BMI } & =\text { body mass index } \\
\text { CF } & =\text { cystic fibrosis } \\
\text { CFRD } & =\text { cystic fibrosis-related diabetes } \\
\text { DM } & =\text { diabetes mellitus } \\
\text { FEV }_{1} & =\text { forced expiratory volume in } 1 \text { second } \\
\text { FVC } & =\text { forced vital capacity } \\
\text { LAS } & =\text { lung allocation score } \\
\text { LTx } & =\text { lung transplantation } \\
\text { UNOS } & =\text { United Network for Organ Sharing }
\end{aligned}
\end{aligned}
$$

There is growing literature describing increased mortality associated with a diagnosis of CFRD and the fact that hyperglycemia is a risk factor for death in patients with $\mathrm{CF}^{5-7}$ To date, there is limited research on the effects of CFRD in patients with CF after LTx. A single-center study of patients with CF found that the prevalence of diabetes mellitus (DM) increased from $29 \%$ (22 out of 77 ) to $49 \%$ (38 out of 77 ) after LTx, and that the median time to developing DM was 80 days, with a range of 13 to 4352 days. $^{8}$ Recently, a retrospective review of the United Network for Organ Sharing (UNOS) database over 3.5 years found that having $\mathrm{CF}$ was significantly associated with the onset of DM after LTx. ${ }^{9}$ With only 2 reported small single-center studies investigating the effects of diabetes on CF after LTx, ${ }^{10,11}$ we sought to assess the effect of DM on survival before and after LTx to address gaps in the medical literature using an available database in the United States. Our hypothesis is that DM at the time of wait listing adversely influences survival both before and after LTx.

\section{METHODS \\ Data Collection}

We retrospectively evaluated data from LTx recipients who were registered in the Organ Procurement and Transplant Network database administered by UNOS. ${ }^{12}$ The study was approved by the Nationwide Children's Hospital Institutional Review Board with a waiver of the need for individual consent (No. 14-00716). The UNOS/Organ Procurement and Transplant Network thoracic database was queried for all patients listed with a CF diagnosis from May 2005 to September 2013. In the pretransplant analysis, first-time LTx candidates who were not transplanted were tracked until death or censoring. The posttransplant analysis included patients with CF who underwent LTx during the same time period. No patients were included in both pre-LTx and post-LTx cohorts, so these groups were independent of each other.

\section{Statistical Analysis}

All analyses were performed using Stata/MP, version 13.1 (StataCorp LP, College Station, Tex). All values were expressed as means \pm standard deviation for continuous measures, and numbers and percentages for categorical variables. For evaluation of differences between baseline characteristics for patients with and without DM, we used unpaired $t$ tests for continuous measures and $\chi^{2}$ tests for dichotomous measures.

For the pretransplant analysis, survival duration, in days, was analyzed from the date of listing until the date of death or censoring. For the posttransplant analysis, survival duration, in days, was analyzed from the date of the transplant until the date of death or censoring. In each of the 2 cohorts (untransplanted and posttransplant patients), survival was first compared across DM status using univariate Cox proportional hazards models and Kaplan-Meier survival curves, with log-rank tests for comparison of curves between patients with and without DM. Multivariate Cox proportional hazards models were used to adjust for potential confounders in each cohort. Covariates included in the analysis of the untransplanted cohort included gender, race, age, creatinine, and body mass index (BMI), and were all assessed at the time of listing. Covariates included in the analysis of transplant outcomes included recipient and donor gender and race, age, creatinine, BMI, and ischemic time, all assessed at the time of transplantation. The Lung Allocation Score (LAS) was considered as an additional covariate, although this measure was a composite of many variables, including DM diagnosis. ${ }^{13}$

Covariates assessed over only part of the study period (forced expiratory volume in 1 second $\left[\mathrm{FEV}_{1}\right]$ and forced vital capacity $[\mathrm{FVC}]$ not available after 2006; 6-minute walk test distance not available after 2008) were not included in multivariate models. Due to the low proportion of missing data on the remaining covariates, listwise deletion was used to construct the sample for multivariate analysis. Continuous covariates were modeled as linearly related to the log hazard of mortality, although the transformation of these covariates using restricted cubic splines did not alter the findings for DM in multivariate Cox models (results available upon request).

Propensity-score matching was performed to compare survival in pairs of DM and non-DM patients matched on the likelihood of having DM at listing. The propensity of DM in CF was calculated separately for each cohort as a logit function of all covariates included in the pretransplant analysis (ie, covariates assessed at the time of listing). Further covariates assessed at listing were added to the propensity models to better account for differences between DM and non-DM populations, and these covariates included history of cigarette smoking, educational attainment, insurance type, and $\mathrm{ABO}$ blood type. To achieve a balance of covariates between DM and non-DM groups in each stratum of the propensity score, both linear and quadratic terms were included for serum creatinine at listing. The matching algorithm used nearest-neighbor matching without replacement on the logit of the propensity score, with a caliper width equal to 0.2 standard deviations of the logit of the propensity score. Standardized differences by DM status were assessed for each covariate to determine the adequacy of the matching algorithm. ${ }^{14}$ Cox proportional hazards regression stratified on the matched pairs was used to estimate a hazard ratio of DM.

\section{RESULTS \\ Pretransplant Analysis}

Figure 1 outlines inclusion criteria for the pretransplant cohort used for our analysis. Of all 136,498 listed thoracic organ transplant candidates, 689 patients with CF qualified for the pretransplant analysis. Further exclusion criteria included 0 days at risk after listing, missing DM data for KaplanMeier survival curve analysis, missing covariate data, and lack of a suitable match for propensity-score matching.

Table 1 summarizes the characteristics of the untransplanted cohort. The only significant differences were on measures of pulmonary function that were discontinued after 2006, with the DM group exhibiting lower $\mathrm{FEV}_{1}$ $(P=.006)$ and FVC $(P=.015)$ compared with the non-DM group. A total of 682 patients with CF listed for LTx were included in univariate survival analysis, of whom 672 had data on DM and were included in Kaplan-Meier analysis. As shown in Table 2, DM was 


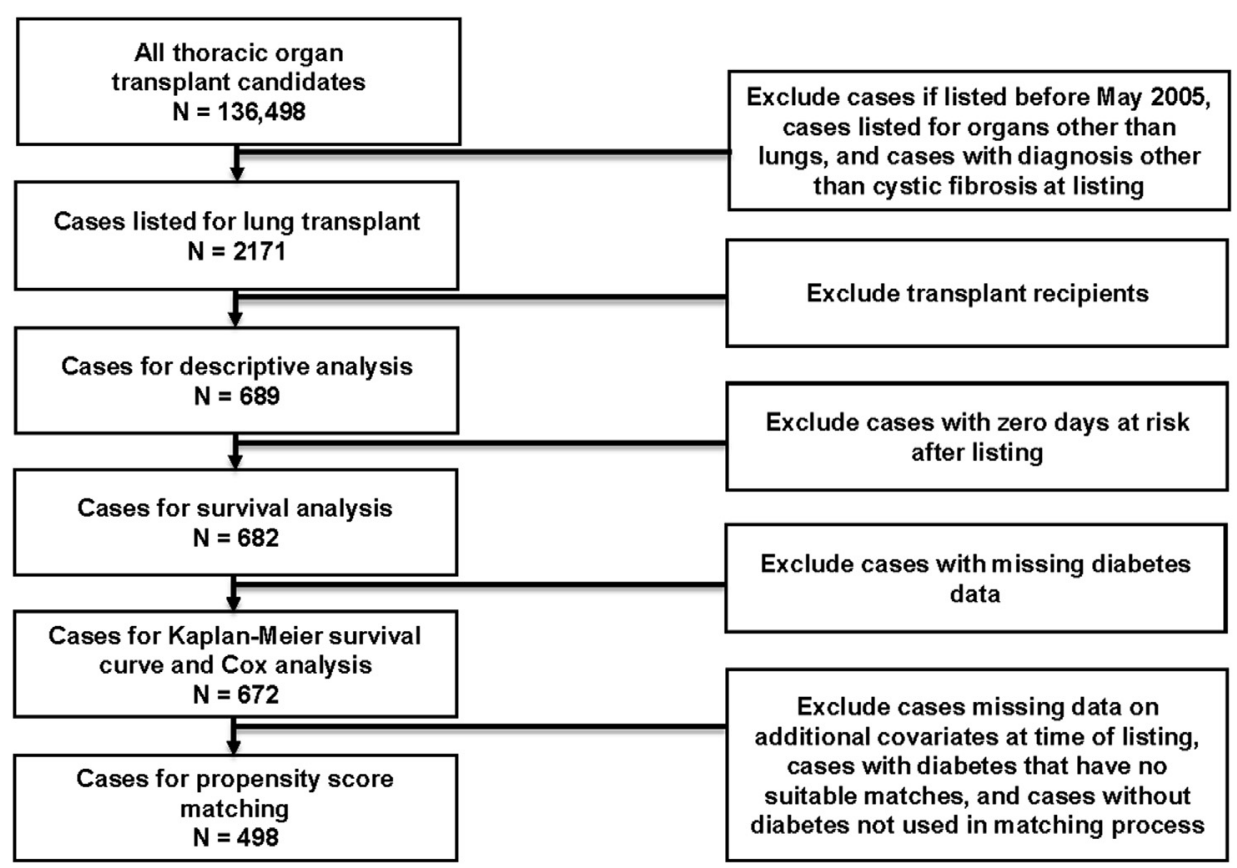

FIGURE 1. Patient inclusion and exclusion criteria for patients with cystic fibrosis listed for lung transplantation but who did not undergo transplant and subsequent univariate analysis, Kaplan-Meier survival curve, multivariate Cox analysis, and propensity-score matching.

associated with significantly increased risk of death (hazard ratio $[\mathrm{HR}], 1.4 ; 95 \%$ confidence interval $[\mathrm{CI}], 1.1-1.9$; $P=.009$ ). Figure 2 illustrates Kaplan-Meier survival curves for the DM and non-DM groups, with shaded $95 \%$ CIs. The numbers of patients at risk in each year since listing are available in Table E1.

In univariate Cox proportional hazards analysis (Table 2), covariates associated with reduced risk of death included higher BMI, higher FEV ${ }_{1}$, higher FVC, and higher 6-minute walk distance. In multivariate Cox proportional hazards analysis (Table 3), DM remained significantly associated with increased mortality hazard among CF patients not undergoing transplant (HR, 1.4; 95\% CI, 1.1-1.8; $P=.012)$.
Higher BMI (HR, 0.91; 95\% CI, 0.86-0.96; $P=.001)$ remained significantly associated with lower mortality hazard. Propensity-score matching confirmed a positive association between DM and mortality hazard using Cox proportional hazards regression stratified on 249 matched pairs $(\mathrm{HR}=1.9 ; 95 \% \mathrm{CI}, 1.2-2.9 ; P=.003)$. The logistic regression model of DM propensity and standardized differences by DM status in the matched sample are shown in Table E2.

\section{Posttransplant Analysis}

Figure 3 outlines inclusion criteria for the cohort of 1482 patients with $\mathrm{CF}$ undergoing transplant. Table 4 summarizes

TABLE 1. Characteristics of a cohort of patients with cystic fibrosis listed for lung transplantation who did not undergo transplant

\begin{tabular}{|c|c|c|c|c|c|c|c|c|}
\hline \multirow[b]{2}{*}{ Variable } & \multicolumn{2}{|c|}{ All $*(n=689)$} & \multicolumn{2}{|c|}{ Diabetes $(n=308)$} & \multicolumn{2}{|c|}{ No diabetes $(n=371)$} & \multicolumn{2}{|c|}{$P$ value } \\
\hline & $\mathbf{N}(\%)$ & Mean \pm SD & $\mathbf{N}(\%)$ & Mean \pm SD & $\mathbf{N}(\%)$ & Mean \pm SD & $t$ test & $\chi^{2}$ \\
\hline Male $(\mathrm{n}=689)$ & $286(42)$ & - & $127(41)$ & - & $154(42)$ & - & - & .94 \\
\hline Race $(n=689)$ & - & - & - & - & - & - & - & .36 \\
\hline White & $621(90)$ & - & $281(91)$ & - & $330(89)$ & - & - & - \\
\hline Black & $9(1.3)$ & - & $5(1.6)$ & - & $4(1.1)$ & - & - & 一 \\
\hline Other & $59(8.6)$ & - & $22(7.1)$ & - & $37(10)$ & - & - & - \\
\hline Age $(y)(n=689)$ & - & $27 \pm 11$ & - & $28 \pm 11$ & - & $26 \pm 11$ & .11 & - \\
\hline Creatinine $(\mathrm{mg} / \mathrm{dL})(\mathrm{n}=688)$ & - & $0.68 \pm 0.43$ & - & $0.69 \pm 0.35$ & - & $0.67 \pm 0.50$ & .49 & - \\
\hline Body mass index $(\mathrm{n}=689)$ & - & $19 \pm 3.0$ & - & $19 \pm 2.8$ & - & $19 \pm 3.1$ & .94 & 一 \\
\hline $\mathrm{FEV}_{1}(\%$ predicted $)(\mathrm{n}=141)$ & - & $30 \pm 11$ & - & $26 \pm 8.3$ & - & $31 \pm 12$ & .006 & - \\
\hline FVC $(\%$ predicted $)(\mathrm{n}=141)$ & - & $46(15)$ & - & $41 \pm 14$ & - & $48 \pm 15$ & .015 & - \\
\hline $6 \mathrm{MWD}(\mathrm{ft} \times 100)(\mathrm{n}=141)$ & - & $10(6.0)$ & - & $9.9 \pm 5.4$ & - & $10 \pm 6.3$ & .77 & - \\
\hline
\end{tabular}

$S D$, Standard deviation; $F E V_{l}$, forced expiratory volume in 1 second; $F V C$, forced vital capacity; $6 M W D$, 6-minute walk distance. *Six hundred seventy-nine cases had data on diabetes. 
TABLE 2. Univariate survival analysis for a cohort of patients with cystic fibrosis listed for lung transplantation who did not undergo transplant $(n=682)$

\begin{tabular}{lcclc}
\hline \multicolumn{1}{c}{ Variable } & N & $\begin{array}{c}\text { Hazard } \\
\text { ratio }\end{array}$ & $\begin{array}{c}\mathbf{9 5} \% \text { Confidence } \\
\text { interval }\end{array}$ & $\boldsymbol{P \text { value }}$ \\
\hline Diabetes & 672 & 1.4 & $1.1-1.9$ & .009 \\
Male & 682 & 0.96 & $0.73-1.3$ & .77 \\
Race & 682 & & & \\
$\quad$ White & & ref & & \\
$\quad$ Black & & 1.9 & $0.85-4.3$ & .12 \\
$\quad$ Other & & 1.1 & $0.73-1.7$ & .58 \\
Age $(\mathrm{y})$ & 682 & 1.0 & $0.99-1.0$ & .83 \\
Creatinine (mg/dL) & 682 & 0.84 & $0.58-1.2$ & .35 \\
Body mass index & 682 & 0.93 & $0.89-0.98$ & .003 \\
FEV $(\%$ predicted $)$ & 138 & 0.93 & $0.90-0.96$ & $<.001$ \\
FVC $(\%$ predicted) & 138 & 0.94 & $0.92-0.96$ & $<.001$ \\
6MWD $(\mathrm{ft} \times 100)$ & 139 & 0.92 & $0.89-0.96$ & $<.001$ \\
\hline
\end{tabular}

ref, Reference category; $F E V_{l}$, forced expiratory volume in 1 second, $F V C$, forced vital capacity, $6 M W D$, 6-minute walk distance.

patient characteristics in this cohort. Significant differences included the patients with DM being less likely to be male, less likely to have a male donor, and having a higher final LAS. Kaplan-Meier curves (Figure 4) show no difference in survival by DM status at listing among 1475 patients who survived at least 1 day since transplant and contributed data on DM status. (The numbers of patients at risk are available in Table E3). Univariate Cox proportional hazards analysis (Table 5) confirmed that DM at listing was not associated with mortality hazard after LTx (HR, 0.99; 95\% CI, 0.82-1.2; $P=.95$ ). Among other independent variables, only age was significantly associated with survival in univariate analysis, with older age predicting lower mortality hazard.

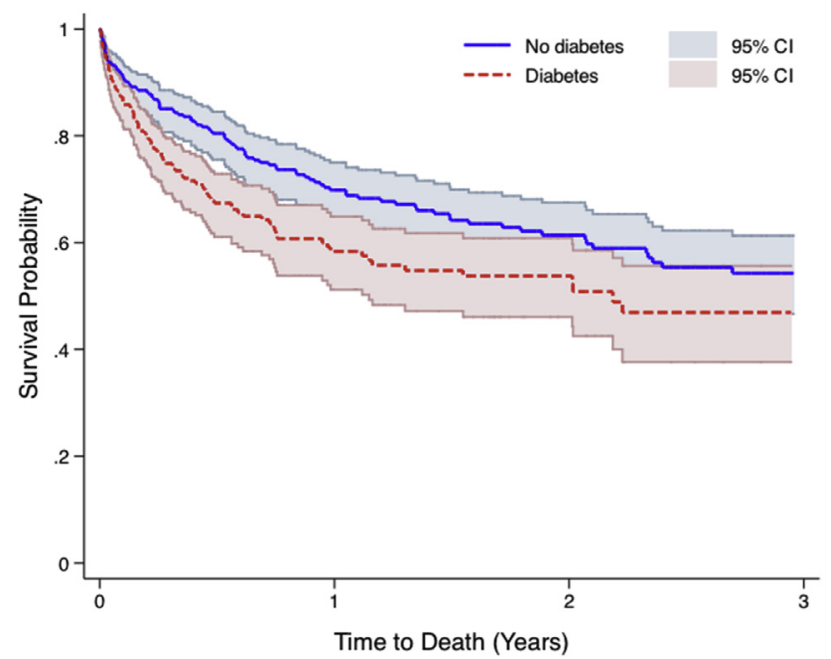

FIGURE 2. Kaplan-Meier survival functions comparing diabetes and no diabetes in patients with cystic fibrosis listed for lung transplantation $(\mathrm{n}=672)$. Log-rank test: $\chi^{2}$ square $_{1}: 6.9 ; P=.0085 . C I$, Confidence interval.
TABLE 3. Multivariate survival analysis for a cohort of patients with cystic fibrosis listed for lung transplantation who did not undergo transplant

\begin{tabular}{lclc}
\hline \multicolumn{1}{c}{ Variable } & Hazard ratio & $\begin{array}{c}\mathbf{9 5} \% \text { Confidence } \\
\text { interval }\end{array}$ & $\boldsymbol{P}$ value \\
\hline Diabetes & 1.4 & $1.1-1.8$ & .012 \\
Male & 1.0 & $0.77-1.3$ & .92 \\
Race & & & \\
$\quad$ White & ref & & \\
$\quad$ Black & 1.9 & $0.84-4.3$ & .12 \\
Other & 1.1 & $0.70-1.7$ & .70 \\
Age (y) & 1.0 & $1.0-1.0$ & .067 \\
Creatinine (mg/dL) & 0.86 & $0.59-1.3$ & .43 \\
Body mass index & 0.91 & $0.86-0.96$ & .001 \\
\hline ref, Reference category. & & &
\end{tabular}

A multivariate Cox proportional hazards model was fitted with all covariates except final LAS, due to the dependence of the LAS on DM status (Table 6, model 1). DM was not significantly associated with survival after LTx (HR, 1.0; $95 \% \mathrm{CI}, 0.82 ; 1.2 ; P=.98)$, and this finding was confirmed when adjusting further for final LAS (Table 6, model 2). Similarly, propensity-score matching using characteristics at listing to predict DM status found no difference in posttransplant survival across DM status in a Cox proportional hazards model stratified on 566 matched pairs (HR, 1.1; $95 \% \mathrm{CI}, 0.82 ; 1.5 ; P=.56)$. The propensity model and standardized differences across DM status in the matched sample are shown in Table E4.

\section{DISCUSSION}

Despite the quickly expanding research investigating DM in patients with CF, limited data exist on clinical outcomes related to DM in patients with CF after LTx, with conflicting results reported in 2 small, single-center studies. In 2011, a study completed in Switzerland ${ }^{10}$ found that DM in patients with $\mathrm{CF}$ improved survival after LTx. However, a study performed earlier in Australia $^{11}$ demonstrated that DM in patients with CF was associated with increased mortality after LTx. Data from the International Society for Heart and Lung Transplantation Registry show that a history of DM was associated with slightly increased risk of death at 5 and 10 years, for the larger LTx cohort, ${ }^{15}$ but no analysis has been done to address the influence on survival specifically in the CF population after LTx. The most important findings from our study include DM is adversely influencing clinical outcomes in CF transplant candidates listed for LTx with no effects on long-term outcomes in the CF population after transplant.

The pathophysiology of DM in CF populations is not completely understood; however, DM in patients with CF is thought to be primarily caused by the destruction of pancreatic islets as a result of fibrosis and fatty infiltration of the pancreas with the progressive deterioration of 


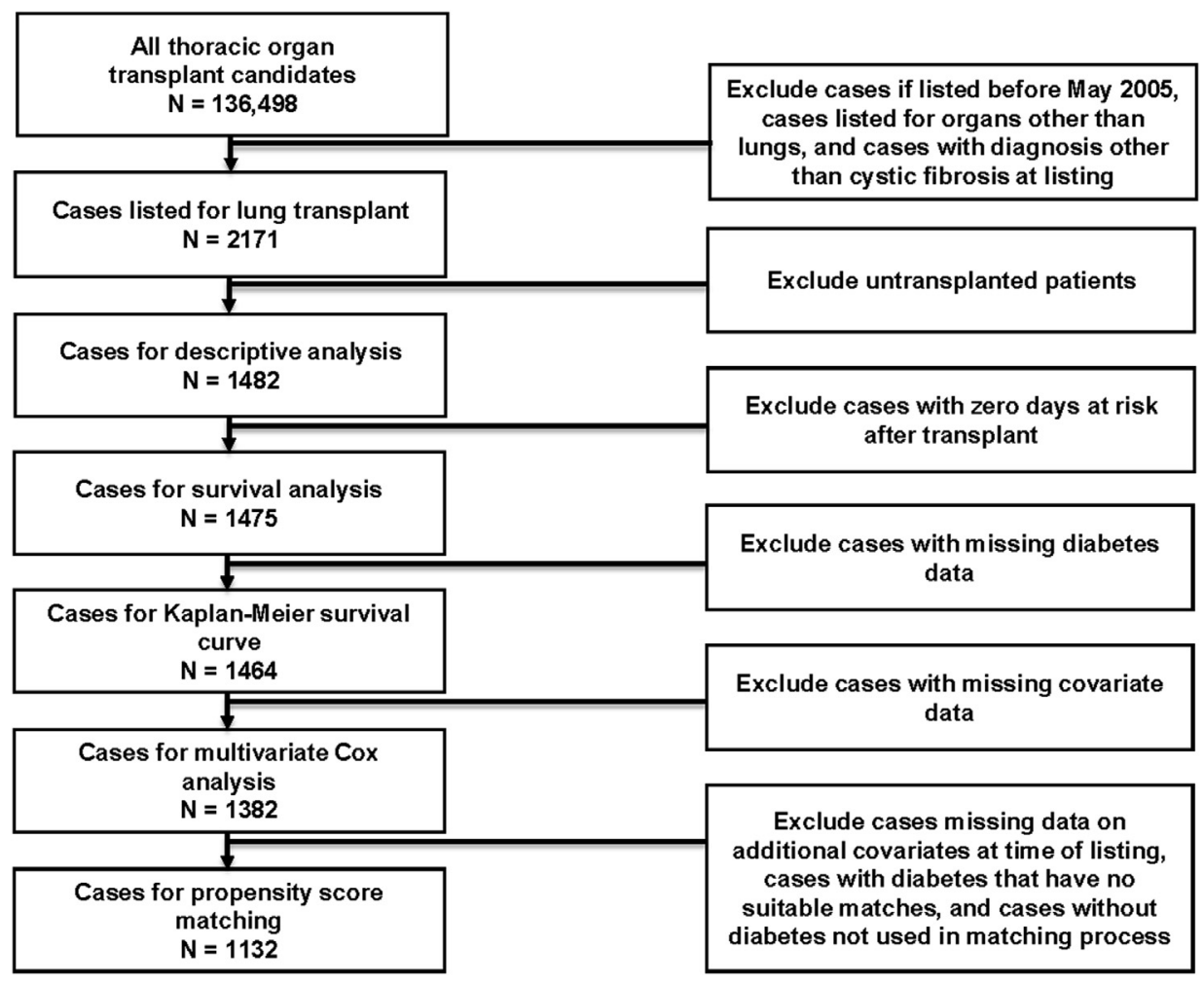

FIGURE 3. Patient inclusion and exclusion criteria for cases with cystic fibrosis after lung transplantation and subsequent univariate analysis, KaplanMeier survival curve, multivariate Cox analysis, and propensity-score matching.

beta-cell function, leading to insulin deficiency. ${ }^{16}$ In comparison to type 1 and $2 \mathrm{DM}$, CFRD has qualities similar to both diseases but distinct differences from both. Regarding the physiology of insulin in DM, type 1 is associated with marked reduction in insulin levels at the onset of disease, whereas type 2 is related to insulin resistance. In CFRD, there is a reduced sensitivity of insulin at the beginning, with eventual progression to reduced insulin levels. ${ }^{17}$ The insulin deficiency in type $1 \mathrm{DM}$ is due to an autoimmune process, whereas destruction of

TABLE 4. Characteristics of a cohort of patients with cystic fibrosis after lung transplant

\begin{tabular}{|c|c|c|c|c|c|c|c|c|}
\hline \multirow[b]{2}{*}{ Variable } & \multicolumn{2}{|c|}{ All* $(n=1482)$} & \multicolumn{2}{|c|}{ Diabetes $(n=682)$} & \multicolumn{2}{|c|}{ No diabetes $(n=789)$} & \multicolumn{2}{|c|}{$P$ value } \\
\hline & $\mathbf{N}(\%)$ & Mean \pm SD & $\mathbf{N}(\%)$ & Mean \pm SD & $\mathbf{N}(\%)$ & Mean \pm SD & $t$ test & $\chi^{2}$ \\
\hline Male recipient $(\mathrm{n}=1482)$ & $777(52)$ & - & $327(48)$ & - & $442(56)$ & - & - & .002 \\
\hline Male donor $(\mathrm{n}=1482)$ & $875(59)$ & - & $379(56)$ & - & $487(62)$ & - & - & .017 \\
\hline Race of recipient $(n=1482)$ & - & - & - & - & - & - & - & .17 \\
\hline White & $1388(94)$ & - & $634(93)$ & - & $743(94)$ & - & - & - \\
\hline Black & $21(1.4)$ & - & $14(2.1)$ & - & $7(0.89)$ & - & - & - \\
\hline Other & $73(4.9)$ & - & $34(5.0)$ & - & $39(4.94)$ & - & - & - \\
\hline Race of donor $(n=1482)$ & - & - & - & - & - & - & - & .85 \\
\hline White & $911(62)$ & - & $421(62)$ & - & $483(61)$ & - & - & - \\
\hline Black & $282(19)$ & - & $132(19)$ & - & 148 (19) & - & - & - \\
\hline Other & $289(20)$ & - & 129 (19) & - & $158(20)$ & - & - & - \\
\hline Age $(y)(n=1482)$ & - & $29 \pm 11$ & - & $29 \pm 10$ & - & $29 \pm 11$ & .95 & - \\
\hline $\begin{array}{l}\text { Creatinine }(\mathrm{mg} / \mathrm{dL}) \\
\quad(\mathrm{n}=1474)\end{array}$ & - & $0.71 \pm 0.44$ & - & $0.72 \pm 0.35$ & - & $0.69 \pm 0.50$ & .23 & - \\
\hline Body mass index $(\mathrm{n}=1480)$ & - & $19 \pm 2.9$ & - & $19 \pm 2.7$ & - & $19 \pm 3.0$ & .18 & - \\
\hline Ischemic time $(\mathrm{h})(\mathrm{n}=1399)$ & - & $5.7 \pm 1.6$ & - & $5.7 \pm 1.6$ & - & $5.7 \pm 1.6$ & .73 & - \\
\hline $\begin{array}{l}\text { Final lung allocation score } \\
\qquad(\mathrm{n}=1471)\end{array}$ & - & $46 \pm 16$ & - & $47 \pm 16$ & - & $45 \pm 16$ & .042 & - \\
\hline
\end{tabular}

$S D$, Standard deviation. *One thousand four hundred seventy-one cases had data on diabetes. 


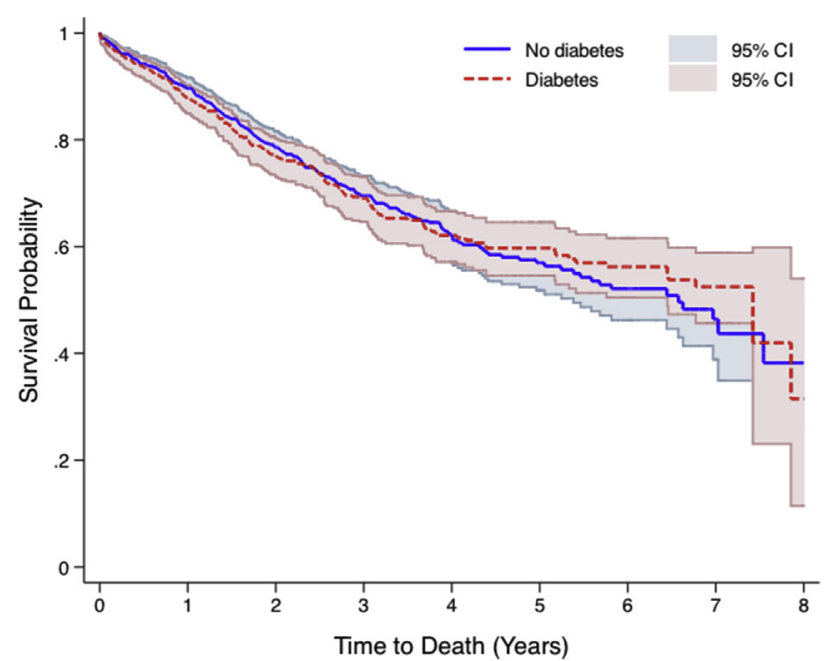

FIGURE 4. Kaplan-Meier survival functions comparing diabetes and no diabetes in patients with cystic fibrosis after lung transplantation $(\mathrm{n}=1464)$. Log-rank test: $\chi^{2}$ square $_{1}: 0.0 ; P=.95 . C I$, Confidence interval.

beta-cell function occurs in CFRD. Although diabetic ketoacidosis is a frequent complication of type $1 \mathrm{DM}$, it rarely occurs in type $2 \mathrm{DM}$ and CFRD. ${ }^{16}$ Additional contributing factors in CFRD include chronic respiratory infections, systemic inflammation, and corticosteroid therapy.

The interactions of the respiratory and endocrine systems in patients with $\mathrm{CF}$ are not well defined. Previous research has shown that DM and glucose intolerance in $\mathrm{CF}$ are strong determinants of pulmonary function and future decline. ${ }^{18,19}$ Data from our study show that patients with $\mathrm{CF}$ on the wait list for LTx have significantly lower $\mathrm{FEV}_{1}$ if they have DM. Although we

TABLE 5. Univariate survival analysis for a cohort of patients with cystic fibrosis after lung transplant $(n=1475)$

\begin{tabular}{lcccc}
\hline \multicolumn{1}{c}{ Variable } & N & $\begin{array}{c}\text { Hazard } \\
\text { ratio }\end{array}$ & $\begin{array}{c}\text { 95\% Confidence } \\
\text { interval }\end{array}$ & $\boldsymbol{P}$ value \\
\hline Diabetes & 1464 & 0.99 & $0.82-1.2$ & .95 \\
Male recipient & 1475 & 1.1 & $0.87-1.3$ & .56 \\
Male donor & 1475 & 0.99 & $0.82-1.2$ & .92 \\
Race of recipient & 1475 & & & \\
$\quad$ White & & ref & & \\
$\quad$ Black & & 1.7 & $0.88-3.3$ & .11 \\
$\quad$ Other & & 1.4 & $0.92-2.0$ & .12 \\
Race of donor & 1475 & & & \\
$\quad$ White & & ref & & .25 \\
$\quad$ Black & & 1.2 & $0.90-1.5$ & .11 \\
$\quad$ Other & & 1.2 & $0.96-1.5$ & .001 \\
Age (y) & 1475 & 0.97 & $0.96-0.98$ & .12 \\
Creatinine (mg/dL) & 1471 & 1.1 & $0.97-1.4$ & .057 \\
Body mass index & 1473 & 0.97 & $0.93-1.0$ & .26 \\
Ischemic time (h) & 1396 & 0.96 & $0.91-1.0$ & \\
Final lung allocation score & 1464 & 1.0 & $1.0-1.0$ & \\
\hline ref, Reference category. & & & &
\end{tabular}

TABLE 6. Multivariate survival analysis for a cohort of patients with cystic fibrosis after lung transplantation

\begin{tabular}{|c|c|c|c|c|c|c|}
\hline \multirow[b]{2}{*}{ Variable } & \multicolumn{3}{|c|}{ Model $1(n=1382)$} & \multicolumn{3}{|c|}{ Model $2(n=1374)$} \\
\hline & HR & $95 \%$ CI & $\begin{array}{c}P \\
\text { value }\end{array}$ & HR & $95 \% \mathrm{CI}$ & $\begin{array}{c}P \\
\text { value }\end{array}$ \\
\hline Diabetes & 1.0 & $0.82-1.2$ & .98 & 0.98 & $0.80-1.2$ & .87 \\
\hline Male recipient & 1.1 & $0.92-1.4$ & .23 & 1.2 & $0.94-1.4$ & .16 \\
\hline Male donor & 0.97 & $0.78-1.2$ & .77 & 0.96 & $0.78-1.2$ & .73 \\
\hline \multicolumn{7}{|l|}{ Race of recipient } \\
\hline White & ref & & & ref & & \\
\hline Black & 1.3 & $0.65-2.6$ & .46 & 1.3 & $0.65-2.7$ & .45 \\
\hline Other & 0.87 & $0.57-1.3$ & .52 & 0.90 & $0.59-1.4$ & .62 \\
\hline \multicolumn{7}{|l|}{ Race of donor } \\
\hline White & ref & & & ref & & \\
\hline Black & 1.1 & $0.82-1.4$ & .66 & 1.1 & $0.86-1.5$ & .41 \\
\hline Other & 1.1 & $0.88-1.4$ & .36 & 1.1 & $0.88-1.4$ & .33 \\
\hline Age (y) & 0.97 & $0.96-0.98$ & $<.001$ & 0.97 & $0.96-0.98$ & $<.001$ \\
\hline Creatinine $(\mathrm{mg} / \mathrm{dL})$ & 1.2 & $1.1-1.4$ & .002 & 1.2 & $1.1-1.4$ & .005 \\
\hline Body mass index & 1.0 & $0.96-1.0$ & .93 & 1.0 & $0.96-1.0$ & .95 \\
\hline Ischemic time (h) & 0.97 & $0.91-1.0$ & .27 & 0.97 & $0.91-1.0$ & .30 \\
\hline Final LAS & & & & 1.0 & $1.0-1.0$ & .016 \\
\hline
\end{tabular}

$\overline{H R \text {, Hazard ratio; } C I \text {, confidence interval; } r e f \text {, reference category; } L A S \text {, lung alloca- }}$ tion score.

cannot determine causality with a retrospective study, our results support previous findings of an association with DM and lower pulmonary function in CF. Further research to address this important issue is needed as it may affect survival in patients with $\mathrm{CF}$ with advanced lung disease.

In addition to a survival difference associated with DM before LTx, our models identified confounders that need to be considered for the allocation of donor lungs. In patients with $\mathrm{CF}$, older age at LTx was associated with improved survival afterward. Compared with influence of older age, higher creatinine at the time of transplant was associated with a significantly higher risk for subsequent mortality. The findings for age may be due to the higher risk of death among adolescents with $\mathrm{CF}$ compared with adults. ${ }^{20,21}$ The findings for creatinine may be related to a medication effect from immunosuppression after LTx. Both of these findings warrant further study beyond the retrospective approach feasible in this database analysis.

Our study is limited by the retrospective collection of data from a large database. This aspect of the study design means that some important confounding variables, such as pulmonary function, were either not measured or measured over only part of the study period. Although missing data were infrequent in the covariates used for the multivariate analyses reported in this study, instances of missing data or data entry errors may have nevertheless influenced the statistical analysis. Furthermore, data on the severity of DM were not 
available at the time of listing, and therefore progression of DM could not be characterized among LTx candidates. Despite its limitations, our study draws results from a large, multi-institutional registry database of transplant candidates and recipients and thus reduces potential biases observed in single-institution studies.

\section{CONCLUSIONS}

We found significantly higher mortality hazard associated with DM in patients with CF who were candidates for LTx who did not undergo transplant, and no relation between DM status at listing and survival of patients with $\mathrm{CF}$ after LTx. These findings reiterate that DM is clinically relevant in patients with $\mathrm{CF}$, especially when being listed for or while awaiting LTx. Therefore, management strategies need further scrutiny to identify optimal methods of treatment to reduce this risk for death. Although DM was a common comorbidity in patients with $\mathrm{CF}$ in the 2 cohorts used for this study, it was not a limiting factor for successful long-term clinical outcomes after LTx.

\section{Conflict of Interest Statement}

Authors have nothing to disclose with regard to commercial support.

The authors thank Dmitry Tumin for his statistical expertise in the data analysis.

\section{References}

1. Ramirez JC, Patterson GA, Winton TL, de Hoyos AL, Miller JD, Maurer JR. Bilateral lung transplantation for cystic fibrosis. The Toronto Lung Transplant Group. J Thorac Cardiovasc Surg. 1992;103:287-93; discussion 294.

2. Starnes VA, Lewiston N, Theodore J, Stoehr C, Stinson E, Shumway NE, et al. Cystic fibrosis. Target population for lung transplantation in North America in the 1990s. J Thorac Cardiovasc Surg. 1992;103:1008-14.

3. Egan TM, Detterbeck FC, Mill MR, Paradowski LJ, Lackner RP, Ogden WD, et al. Improved results of lung transplantation for patients with cystic fibrosis. J Thorac Cardiovasc Surg. 1995; 109:224-34; discussion 234-5.

4. Adler AI, Shine BS, Chamnan P, Haworth CS, Bilton D. Genetic determinants and epidemiology of cystic fibrosis-related diabetes: results from a British cohort of children and adults. Diabetes Care. 2008;31:1789-94.

5. Adler AI, Shine B, Haworth C, Leelarathna L, Bilton D. Hyperglycemia and death in cystic fibrosis-related diabetes. Diabetes Care. 2011;34:1577-8.
6. Moran A, Dunitz J, Nathan B, Saeed A, Holme B, Thomas W. Cystic fibrosisrelated diabetes: current trends in prevalence, incidence, and mortality. Diabetes Care. 2009;32:1626-31.

7. Chamnan P, Shine BS, Haworth CS, Bilton D, Adler AI. Diabetes as a determinant of mortality in cystic fibrosis. Diabetes Care. 2010;33:311-6.

8. Hadjiliadis D, Madill J, Chaparro C, Tsang A, Waddell TK, Singer LG, et al. Incidence and prevalence of diabetes mellitus in patients with cystic fibrosis undergoing lung transplantation before and after lung transplantation. Clin Transplant. 2005; 19:773-8.

9. Ye X, Kuo HT, Sampaio MS, Jiang Y, Bunnapradist S. Risk factors for development of new-onset diabetes mellitus after transplant in adult lung transplant recipients. Clin Transplant. 2011;25:885-91.

10. Hofer M, Schmid C, Benden C, Speich R, Inci I, Weder W, et al. Diabetes mellitus and survival in cystic fibrosis patients after lung transplantation. J Cyst Fibros. 2012;11:131-6.

11. Bradbury RA, Shirkhedkar D, Glanville AR, Campbell LV. Prior diabetes mellitus is associated with increased morbidity in cystic fibrosis patients undergoing bilateral lung transplantation: an 'orphan' area? A retrospective case-control study. Intern Med J. 2009;39:384-8.

12. United Network for Organ Sharing/Organ Procurement and Transplantation Network Standard Transplant Analysis and Research Database. Available at: http://optn.transplant.hrsa.gov/data/about/OPTNDatabase.asp. Accessed September 6, 2013.

13. United Network for Organ Sharing. Guide to calculating the Lung Allocation Score. Available at: https://www.unos.org/docs/lung_allocation_score.pdf. Accessed April 30, 2015.

14. Austin PC. An introduction to propensity score methods for reducing the effects of confounding in observational studies. Multivariate Behav Res. 2011;46: 399-424.

15. Yusen RD, Christie JD, Edwards LB, Kucheryavaya AY, Benden C, Dipchand AI, et al. The Registry of the International Society for Heart and Lung Transplantation: thirtieth adult lung and heart-lung transplant report-2013; focus theme: age J Heart Lung Transplant. 2013;32:965-78.

16. Lek N, Acerini CL. Cystic fibrosis related diabetes mellitus - diagnostic and management challenges. Curr Diabetes Rev. 2010;6:9-16.

17. Hameed S, Jaffé A, Verge CF. Cystic fibrosis related diabetes (CFRD)-the end stage of progressive insulin deficiency. Pediatr Pulmonol. 2011;46:747-60.

18. Rosenecker J, Höfler R, Steinkamp G, Eichler I, Smaczny C, Ballmann M, et al Diabetes mellitus in patients with cystic fibrosis: the impact of diabetes mellitus on pulmonary function and clinical outcome. Eur J Med Res. 2001;6:345-50.

19. Milla CE, Warwick WJ, Moran A. Trends in pulmonary function in patients with cystic fibrosis correlate with the degree of glucose intolerance at baseline. Am J Respir Crit Care Med. 2000;162:891-5.

20. Hayes D Jr, McCoy KS, Whitson BA, Mansour HM, Tobias JD. High-risk age window for mortality in children with cystic fibrosis after lung transplantation. Pediatr Transplant. 2015;19:206-10.

21. Thabut G, Christie JD, Mal H, Fournier M, Brugière O, Leseche G, et al. Survival benefit of lung transplant for cystic fibrosis since lung allocation score implementation. Am J Respir Crit Care Med. 2013;187:1335-40.

Key Words: advanced lung disease, cystic fibrosis, diabetes mellitus, lung transplantation, survival 
TABLE E1. Logistic regression results predicting diabetes at listing, and standardized differences across diabetes status after propensity-score matching, in a cohort of patients with cystic fibrosis listed for lung transplantation but did not undergo transplant

\begin{tabular}{|c|c|c|c|c|}
\hline \multirow[b]{2}{*}{ Variable } & \multicolumn{3}{|c|}{ Logistic regression model $(n=627)$} & \multirow{2}{*}{$\frac{\text { Matched sample }(n=498)}{\text { Standardized difference* }}$} \\
\hline & Odds ratio & $\mathbf{9 5} \%$ Confidence interval & $P$ value & \\
\hline Male & 0.94 & $0.66-1.3$ & .71 & 0.057 \\
\hline \multicolumn{5}{|l|}{ Race } \\
\hline White & ref & & & 0.066 \\
\hline Black & 1.5 & $0.40-6.0$ & .53 & 0 \\
\hline Other & 1.1 & $0.61-2.1$ & .68 & 0.072 \\
\hline Age (y) & 0.99 & $0.97-1.0$ & .27 & 0.0076 \\
\hline Creatinine (mg/dL) & 2.4 & $0.79-7.1$ & .12 & 0.039 \\
\hline Creatinine squared & 0.81 & $0.59-1.1$ & .18 & \\
\hline Body mass index & 0.97 & $0.91-1.0$ & .38 & 0.020 \\
\hline History of cigarette smoking & 1.8 & $0.71-4.4$ & .22 & 0 \\
\hline \multicolumn{5}{|l|}{ Educational attainment } \\
\hline Grade school or less & ref & & & 0.027 \\
\hline High school & 2.1 & $1.1-4.0$ & .019 & 0.066 \\
\hline Attended college, no degree & 2.7 & $1.3-5.3$ & .005 & 0.027 \\
\hline College degree & 3.3 & $1.6-7.1$ & .002 & 0.072 \\
\hline Advanced degree & 4.1 & $1.6-10$ & .003 & 0.033 \\
\hline Public insurance & 1.3 & $0.93-1.8$ & .13 & 0.0081 \\
\hline \multicolumn{5}{|l|}{ Blood type } \\
\hline A & ref & & & 0.016 \\
\hline $\mathrm{AB}$ & 0.85 & $0.30-2.4$ & .76 & 0 \\
\hline B & 1.1 & $0.59-1.9$ & .85 & 0.013 \\
\hline $\mathrm{O}$ & 0.87 & $0.62-1.2$ & .44 & 0.008 \\
\hline
\end{tabular}

ref, Reference category. *Absolute values of standardized differences are shown.

TABLE E2. Logistic regression results predicting diabetes at listing, and standardized differences across diabetes status after propensity-score matching, in a cohort of patients with cystic fibrosis listed for lung transplantation but who did not undergo transplant

\begin{tabular}{|c|c|c|c|c|}
\hline \multirow[b]{2}{*}{ Variable } & \multicolumn{3}{|c|}{ Logistic regression model $(n=627)$} & \multirow{2}{*}{$\begin{array}{l}\text { Matched sample }(n=498) \\
\text { Standardized difference* }\end{array}$} \\
\hline & OR & $95 \% \mathbf{C I}$ & $P$ value & \\
\hline Male & 0.94 & $0.66-1.3$ & .71 & 0.057 \\
\hline \multicolumn{5}{|l|}{ Race } \\
\hline White & ref & & & 0.066 \\
\hline Black & 1.5 & $0.40-6.0$ & .53 & 0 \\
\hline Other & 1.1 & $0.61-2.1$ & .68 & 0.072 \\
\hline $\operatorname{Age}(y)$ & 0.99 & $0.97-1.0$ & .27 & 0.0076 \\
\hline Creatinine $(\mathrm{mg} / \mathrm{dL})$ & 2.4 & $0.79-7.1$ & .12 & 0.039 \\
\hline Creatinine squared & 0.81 & $0.59-1.1$ & .18 & \\
\hline Body mass index & 0.97 & $0.91-1.0$ & .38 & 0.020 \\
\hline History of cigarette smoking & 1.8 & $0.71-4.4$ & .22 & 0 \\
\hline \multicolumn{5}{|l|}{ Educational attainment } \\
\hline Grade school or less & ref & & & 0.027 \\
\hline High school & 2.1 & $1.1-4.0$ & .019 & 0.066 \\
\hline Attended college, no degree & 2.7 & $1.3-5.3$ & .005 & 0.027 \\
\hline College degree & 3.3 & $1.6-7.1$ & .002 & 0.072 \\
\hline Advanced degree & 4.1 & $1.6-10$ & .003 & 0.033 \\
\hline Public insurance & 1.3 & $0.93-1.8$ & .13 & 0.0081 \\
\hline \multicolumn{5}{|l|}{ Blood type } \\
\hline A & ref & & & 0.016 \\
\hline $\mathrm{AB}$ & 0.85 & $0.30-2.4$ & .76 & 0 \\
\hline $\mathrm{B}$ & 1.1 & $0.59-1.9$ & .85 & 0.013 \\
\hline $\mathrm{O}$ & 0.87 & $0.62-1.2$ & .44 & 0.008 \\
\hline
\end{tabular}

$O R$, Odds ratio; $C I$, confidence interval; ref, reference category. *Absolute values of standardized differences are shown. 
TABLE E3. Number of patients at risk, by diabetes status and year since transplant, among a cohort of patients with cystic fibrosis who underwent lung transplant

\begin{tabular}{lcc}
\hline & \multicolumn{2}{c}{ Patients at risk } \\
\cline { 2 - 3 } Years since transplant & No diabetes & Diabetes \\
\hline 0 & 785 & 679 \\
1 & 577 & 478 \\
2 & 401 & 337 \\
3 & 273 & 225 \\
4 & 180 & 157 \\
5 & 98 & 107 \\
6 & 62 & 58 \\
7 & 22 & 25 \\
\hline
\end{tabular}

TABLE E4. Logistic regression results predicting diabetes at listing, and standardized differences across diabetes status after propensity-score matching, in a cohort of patients with cystic fibrosis undergoing lung transplant

\begin{tabular}{|c|c|c|c|c|}
\hline \multirow[b]{2}{*}{ Variable } & \multicolumn{3}{|c|}{ Logistic regression model $(n=1359)$} & \multirow{2}{*}{$\frac{\text { Matched sample }(n=1132)}{\text { Standardized difference }^{*}}$} \\
\hline & OR & $95 \%$ CI & $P$ value & \\
\hline Male & 0.67 & $0.53-0.84$ & .001 & 0.064 \\
\hline \multicolumn{5}{|l|}{ Race } \\
\hline White & ref & & & 0.016 \\
\hline Black & 3.0 & $1.0-9.0$ & .048 & 0.034 \\
\hline Other & 1.1 & $0.68-1.9$ & .63 & 0.0082 \\
\hline Age (y) & 0.99 & $0.98-1.0$ & .41 & 0.031 \\
\hline Creatinine $(\mathrm{mg} / \mathrm{dL})$ & 2.9 & $1.1-7.9$ & .036 & 0.029 \\
\hline Creatinine squared & 0.69 & $0.45-1.0$ & .079 & \\
\hline Body mass index & 1.0 & $0.98-1.1$ & .39 & 0.011 \\
\hline History of cigarette smoking & 1.0 & $0.63-1.7$ & .89 & 0.023 \\
\hline \multicolumn{5}{|l|}{ Educational attainment } \\
\hline Grade school or less & ref & & & 0.032 \\
\hline High school & 1.8 & $1.1-3.1$ & .025 & 0.0037 \\
\hline Attended college, no degree & 1.9 & $1.1-3.3$ & .026 & 0.015 \\
\hline College degree & 1.6 & $0.9-2.9$ & .11 & 0.0043 \\
\hline Advanced degree & 1.8 & $0.88-3.7$ & .11 & 0 \\
\hline Public insurance & 1.2 & $0.98-1.5$ & .081 & 0.014 \\
\hline \multicolumn{5}{|l|}{ Blood type } \\
\hline A & ref & & & 0.0071 \\
\hline $\mathrm{AB}$ & 1.1 & $0.59-2.1$ & .76 & 0.021 \\
\hline B & 0.85 & $0.58-1.26$ & .43 & 0.044 \\
\hline $\mathrm{O}$ & 1.1 & $0.84-1.34$ & .63 & 0.025 \\
\hline
\end{tabular}

$O R$, Odds ratio; $C I$, confidence interval; ref, reference category. *Absolute values of standardized differences are shown. 